\title{
A procedure for stable electrical measurements on a rock sample against high contact resistance as a prerequisite for electrical tomography
}

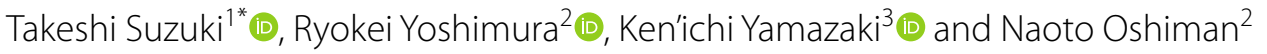

\begin{abstract}
As a basis for the electrical tomography of laboratory-scale rock samples $(\sim 10 \mathrm{~cm})$, we developed a procedure for stable, multi-point, electrical measurement on rock samples that is effective even at high contact and sample resistance. Electrodes were strongly attached to the surface of high-resistivity rock using conductive and adhesive epoxy. Sustained current injection for long periods into high-resistance rocks was fulfilled using a constant direct current source with high internal resistance. Accurate voltage measurement across the high-resistance rock was accomplished by differential measurement using two high input resistance voltmeters. Measurements of high resistance also require a stable measurement environment: the temperature and humidity in the laboratory were controlled using an air conditioner, a humidifier, a dehumidifier, and a vinyl tent. Signal noise arising from human activities was eliminated by the remote operation of the measuring equipment and switching terminal. The proposed measurement procedure was evaluated in terms of the stability and accuracy of measured values and its applicability to electrical tomography. To assess measurement stability, we performed multiple measurements of a dry granite sample at various levels of absolute humidity. Our procedure recorded highly reproducible measurements under each humidity condition. The observed changes in measured values with absolute humidity indicate the importance of stabilising the temperature and humidity conditions in the laboratory. Applying our technique to multiple plastic samples with known resistivity confirmed its accuracy. To evaluate its applicability to electrical tomography, we measured the potential distribution on a dry granite surface in response to an injected current using a simple 40-electrode array. The potential distribution measured by our procedure agreed well with that predicted by forward modelling, demonstrating the robustness of our procedure in array measurements, and thus indicating its potential applicability to tomographic measurements for a variety of targets even under severe conditions including the relative dryness of ambient humidity.
\end{abstract}

Keywords: Multi-point measurement, Small electrode, Current injection, Voltage measurement, Resistivity measurement, Contact resistance, Absolute humidity, Differential method, Granite, Measurement environment

\footnotetext{
*Correspondence: suzuki.takeshi.38n@st.kyoto-u.ac.jp

1 Graduate School of Science, Kyoto University, Gokasho, Uji, Kyoto

611-0011, Japan

Full list of author information is available at the end of the article
}

\begin{abstract}
Introduction
Electrical resistivity estimated through geo-electromagnetic observations is crucial to understanding underground strata and their compositions. Its spatial variation qualitatively reflects the tectonic and geological setting. However, quantitative interpretation of the obtained resistivity and its spatial variation is not easy because subsurface resistivity is complexly affected by
\end{abstract}


many factors. Its proper interpretation requires a good understanding of the rocks' electrical properties. Therefore, electrical measurements of a variety of rock samples across a wide range of conditions and spatial scales are essential.

Previous studies have measured the resistivities of various rock samples in a variety of conditions. For example, Brace et al. (1965) measured the resistivity of granite saturated with salt and tap water at high pressure. Coster (1948) measured the resistivity of granite, gabbro, basalt, peridotite, gneiss, and eclogite at various temperatures up to $1000^{\circ} \mathrm{C}$. Fuji-ta et al. (2004) studied the electrical resistivity of granulite at $1.0 \mathrm{GPa}$ and $300-890 \mathrm{~K}$, and Fuji-ta et al. (2007) investigated the electrical resistivity of gneiss at $1.0 \mathrm{GPa}$ and up to $1000 \mathrm{~K}$. These previous studies focused only on the bulk resistivity of rock samples. Kariya and Shankland (1983) systematically discussed the properties of bulk resistivity by compiling experimental results. In contrast, few experiments have measured the internal resistivity structure of rocks, despite its potential usefulness in providing important information for the interpretation of electromagnetic survey results.

At present, anomalies or contrasts detected by electromagnetic surveys in their resolvable scale (i.e. on the order of $\mathrm{km}$ ) are frequently interpreted as smaller-scale structures such as fault planes and rupture zones. However, this interpretation is uncertain, because the appearances of small-scale structures in electrical resistivity in larger-scale electrical resistivity images or the resistivities of constituents in bulk resistivity values have not been clarified. As such, it is currently difficult to isolate and identify the factors that affect large-scale resistivity. Investigation at field scale $(\sim \mathrm{km})$ is generally impossible. However, laboratory-scale study is possible: it is easy to prepare rocks that contain small-scale structures such as fractures caused by compression tests and to image the internal structures (i.e. fractures) of the rocks using nondestructive methods such as X-ray CT scanning (e.g., Kawakata et al. 1999). If we can determine the internal structures of a given sample together with the bulk resistivity, we may be able to establish quantitative descriptions of electrical resistivity at different spatial scales by comparison. This might facilitate the obtaining of fieldscale results by extrapolation. This background strongly motivated us to establish a suitable measurement technique for using electrical tomography to image the internal structure of rocks.

In order to investigate the internal resistivity structure of a rock sample, the potential distribution on its surface must be measured with a sufficient spatial resolution by using multiple small electrodes attached to it. In addition, large samples are inevitable when measuring artificially fractured rocks, because the precisely controlled compression required to make fractures cannot be applied to small samples. Therefore, measurements must use small electrodes and the sample must be large in order to allow a measurement array to be applied without the electrodes overlapping. The small size of the electrodes and the large size of the sample inevitably increase the contact resistance and sample resistance, respectively, hampering stable current injection and voltage measurement. To conduct electrical tomography for rock samples, we must develop a technique for measurements that overcomes these difficulties.

Similar challenges have been faced not only in geophysics, but also in diverse fields including medical imaging (e.g., Holder et al. 1996; Meier et al. 2008), chemical engineering (e.g., Dickin and Wang 1996) and civil engineering (e.g., Karhunen et al. 2010). Electrical measurements are not difficult in medical imaging and chemical engineering, because the resistivity of the measurement target is low (up to $100 \Omega \mathrm{m}$ ). In contrast, electrical measurement in civil engineering faces restrictions. Although Karhunen et al. (2010) detected impurities such as plastic plates in sufficiently moistened concrete blocks, they also considered that future research ought to solve the problem of contact impedance instability encountered when taking electrical measurements of dry concrete.

Difficulties in measurement related to high sample resistance and contact resistance emerge most severely in geophysics. Borsic et al. (2005) imaged a mass of clay embedded in sand, and Stacey (2006) imaged the diffusion process of salt water in Berea sandstone. These measurements were performed on only high-porosity samples under high water-saturation, and thus avoided the major difficulties of high contact and sample resistance. Stacey (2006) reported that electrical tomography can only be performed with sufficient water-saturation to provide proper connectivity between the rock surface and electrodes. Establishing a reliable procedure for resistivity measurements involving high sample and high contact resistances remains a significant challenge, but it would increase the information available on the electrical properties of rocks by allowing electrical tomography of various rocks under various conditions.

This study aimed to develop a reliable procedure for stable multi-point electrical measurements on a rock sample with high contact resistance. To make the procedure compatible with as wide a range of measurement conditions as possible, the designed method was applied to an extreme experimental condition; that is measuring dry rock at ambient temperature (about $300 \mathrm{~K}$ ) and pressure (about $100 \mathrm{kPa}$ ), under which the contact and sample resistances are particularly high.

The remainder of this paper is organised as follows: "Measurement requirements" section enumerates the 
requirements for stable multi-point electrical measurements on a rock sample with high contact resistance. "Proposed measurement procedure" section proposes a measurement procedure that fulfils these requirements. "Example of the experimental set-up" section describes the experimental set-up to test the method's performance. "Stability and validity of measurements" section assesses the stability and validity of the measured values and demonstrates the efficiency of the proposed procedure. "Electrical measurements using an electrode array" section examines electrical measurements of a dry granite sample with many electrodes in a simple configuration as the first step towards electrical tomography. "Conclusions" section presents the conclusions.

\section{Measurement requirements}

Stable electrical measurements with small electrodes on rock samples against high sample and contact resistance have the following requirements regarding the electrodes, current sources, voltmeters, noise reduction, and measurement environment.

\section{Electrodes}

The measurement electrodes should be strongly attached with high conductivity, even when electrodes of arbitrary shape are used on the surfaces of dry rocks. Previous studies have employed metal plate electrodes of silver, molybdenum, or brass (e.g., Collett 1959; Fuji-ta et al. 2004; Borsic et al. 2005). However, metal plates do not contact the sample unless the sample surface is sufficiently wet or under confining pressure. Even in experiments with wet samples, a porous filter paper is often placed between the wet sample and electrode to connect them with the fluid. It is necessary for electrodes to be attachable to dry rocks at room temperature and pressure.

\section{Current injection}

Electrical current must be injected into a high-resistance rock for a long period during measurement. Previous studies have employed function generators for current injection (e.g., Fuji-ta et al. 2004). However, common function generators are incompatible with very-highresistance samples due to difficulties in applying high voltage and controlling the micro-current.

\section{Voltage measurement}

The voltage across a dry, high-resistance rock should be measured accurately. The conventional multimeters used in previous studies are not suitable for measuring voltage at high resistance (over about $10 \mathrm{G} \Omega$ ) due to their low internal resistance. The voltmeter must have an internal resistance far greater than the target resistance.

\section{Noise reduction}

The measurement procedure should be designed to reduce expected noise in measurements at high resistance. This includes noise from the power supply, because even minute variations in the current have a large effect, owing to the injected current being very small in a highresistance sample. Current leakage from insulation in the measurement circuit needs to be prevented. In highresistance measurements, if the insulation and samples have similar resistance, then injected current would flow through both.

\section{Measurement environment}

High-resistance measurement also requires a stable measurement environment with little variation in temperature, humidity, and other environmental conditions. As the current flow is very low, changes in the measurement environment can significantly affect measurements. Electrical measurements of rocks can be affected by atmospheric humidity when conducted at ambient temperature and pressure. Okuyama (1973) and Alvarez (1973) reported that the resistance and resistivity of dry rock changed greatly with the surrounding moisture conditions. With regard to the response of minerals to humidity, Soffer and Folman (1966), Colomer and Anderson (2001), and Umezawa et al. (2018) reported variations in the electrical conductivity of silica gel and silica nanoparticles with changing humidity.

\section{Proposed measurement procedure}

The current-injection and voltage-measurement techniques described here address the problems enumerated in the previous section regarding stable multi-point electrical measurements against high resistance.

\section{Electrodes}

Favourable properties in the measuring electrodes are achieved through using a conductive adhesive comprising uniformly dispersed conductive particles (e.g., silver) in an epoxy resin organic binder. The conductive adhesive allows arbitrary arrangements and shapes of the electrodes. Furthermore, it provides stable attachment for all surface types.

\section{Current injection}

To achieve current injection at high resistance, the system for current injection and voltage measurement is designed as shown in Fig. 1; it is compared alongside a conventional measuring circuit. Our method uses a constant direct current source with high internal resistance in the same manner as Yamashita et al. (2014). There are two ways of finding resistance: measuring current under constant applied voltage and measuring voltage 


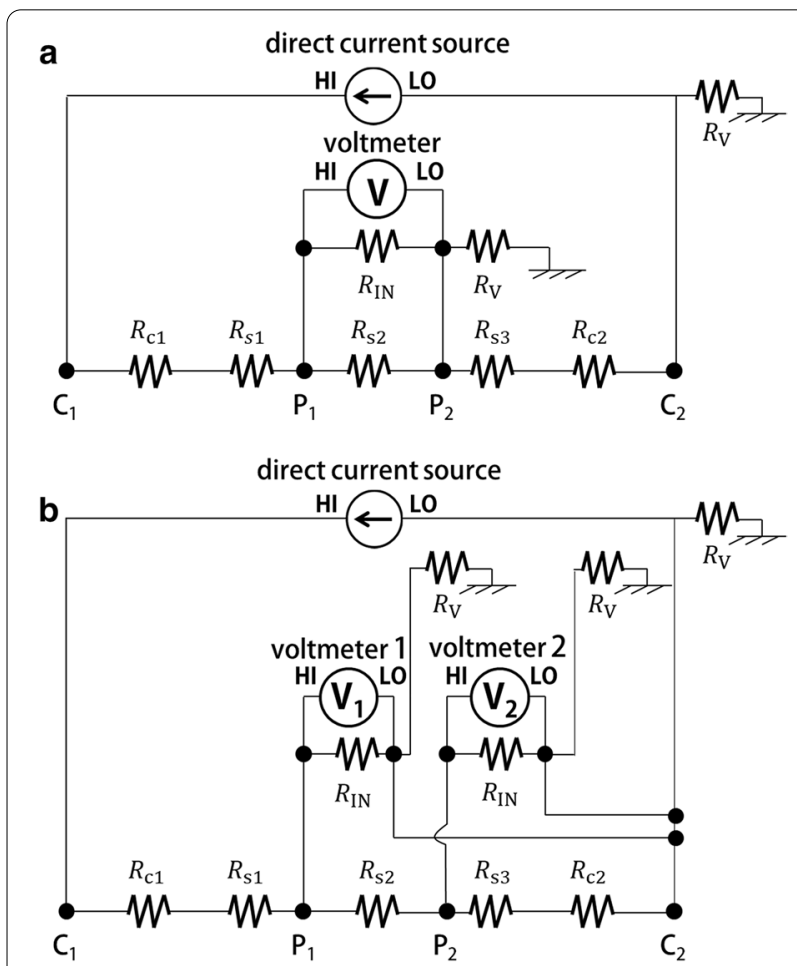

Fig. 1 Circuitry of a the conventional four-terminal method and $\mathbf{b}$ the differential measurement method adopted here. $R_{\mathbb{I N}}$ is input resistance, $R_{\mathrm{V}}$ is the insulation resistance between the negative terminal and chassis ground, $R_{c}$ is the contact resistance between the electrode and sample surface, and $R_{s}$ is the sample resistance. $\mathrm{HI}$ labels positive terminals, $\mathrm{LO}$ labels negative terminals, $C_{1}$ and $C_{2}$ are current electrodes, $P_{1}$ and $P_{2}$ are potential electrodes. In $\mathbf{a}$ when the sum of $R_{\mathrm{s} 3}$ and $R_{\mathrm{C} 2}$ is much smaller than $R_{\mathbb{I N}}$ or $R_{\mathrm{V}}$, no current flows into the voltmeter. However, in a voltmeter, $R_{\mathrm{V}}$ is usually much smaller than $R_{\mathbb{I N}}$. When $R_{\mathrm{V}}$ is less than the sum of $R_{\mathrm{s} 3}$ and $R_{\mathrm{c} 2}$ current flows into $R_{\mathrm{V}}$ through the negative terminal of the voltmeter, preventing correct voltage measurement. $\ln \mathbf{b}, R_{V}$ does not contribute to the current path, and when $R_{\mathbb{I N}}$ is larger than the sum of $R_{\mathrm{s} 3}$ and $R_{\mathrm{c} 2}$, most of the current does not flow to the voltmeter. The differential method uses two voltmeters, whose positive terminals are connected to $P_{1}$ and $P_{2}$, and whose negative terminals are shorted to the negative terminal of the current source. The voltage between $P_{1}$ and $P_{2}$ is obtained as the voltage difference between the measured values of $V_{1}$ and $V_{2}$. In addition to this circuitry, the guarding to reduce current leakage is adopted as described in the main text; however, the shield is not drawn in this figure to avoid complexity of the diagram. See, for example, Figs. 2-5 and Fig. 2-39c of Tektronix (2016) for a detailed explanation of the guarding

under constant current. A very high contact resistance can effectively be evaluated by measuring current under a constant applied voltage. Direct current (DC) was selected here for its suitability for high-resistance measurements, which arises for the following reasons. First, applying alternating current $(\mathrm{AC})$ to a high-resistance sample that exceeds $1 \mathrm{G} \Omega$ is difficult and few instruments can facilitate this. Second, the transient response time of the measured value is not negligible for highresistance measurements using AC. In contrast, using DC does not include these difficulties. In addition, it is not necessary to consider the influence of the skin effect on DC measurements. Therefore, we decided to use DC in our measurements.

\section{Voltage measurement}

The proposed method ensures accurate voltage measurement by differential measurement using two voltmeters with high input resistance. In the resistance measurement of dry rock, insulation resistance between the negative terminal and chassis ground may be smaller than the sum of the sample and contact resistance, allowing current to leak from the negative terminal of the voltmeter. Even using a voltmeter with high input resistance [as used by Yamashita et al. (2014)], current can leak with the conventional four-terminal circuit shown in Fig. 1a, because the insulation resistance is usually much smaller than the input resistance. This problem is solved by shorting the negative terminal of the high input resistance voltmeter to the negative terminal of the current source. However, this short circuit causes the measured voltage to include a voltage drop by the contact resistance of the negative current electrode and potential fluctuation at the signal ground of the current source. This study uses the differential measurement shown in Fig. $1 \mathrm{~b}$ to eliminate the above effects. The difference between the outputs of the two voltmeters yields the potential difference, while the signals common to both voltmeters cancel.

\section{Noise reduction}

The differential measurement circuit has the voltage common to the negative terminals. Its common voltage is separated from the chassis ground of the measurement instruments. The chassis ground is also separated from the earth ground to remove noise from the power supply. The guarding described by Tektronix (2016) is adopted to reduce current leakage from the measurement cables. It is applied to the wiring from the measurement instrument to the switch unit and sets the shield of the coaxial cable at the same potential as the inner conductor. When the shield is at the same potential as the inner conductor, there is no current flow between them. Therefore, this technique greatly reduces current leakage in the cable.

\section{Measurement environment}

All measurements are performed with temperature and humidity kept as constant as possible using a humidifier, dehumidifier, and an air conditioner to reduce changes of sample resistance due to fluctuations in atmospheric moisture. 
Human disturbance (e.g., vibration of the measurement circuit when attaching/detaching terminals and handling samples, and changes in temperature and humidity when staff enter or leave the laboratory) can cause strong signal noise; therefore, the proposed method employs remote operation of the instruments and a switching terminal to reduce signal noise arising from human activities.

\section{Example of the experimental set-up}

The performance of the proposed method was assessed in a test measurement using the sample, tools, and instruments described here.

The cylindrical granite measurement target $(52 \mathrm{~mm}$ diameter, $100 \mathrm{~mm}$ length; white granite from China) used in the test is shown in Fig. 2a. Its ends were ground parallel, and the surface was not polished. This study used granite as a measurement target, because it is a typical rock component of the upper crust. As we hope to apply our measuring procedure to electrical tomography using dozens of electrodes, our procedure should be evaluated using a relatively large sample capable of hosting many electrodes without overlap. To confirm the performance of the method applied to a sample with high contact and sample resistance, we used dried granite at ambient temperature and pressure.

\section{Electrodes}

The electrodes were conductive epoxy adhesive (CW2400 Epoxy, Chemtronics, Mansfield, England). At any size it
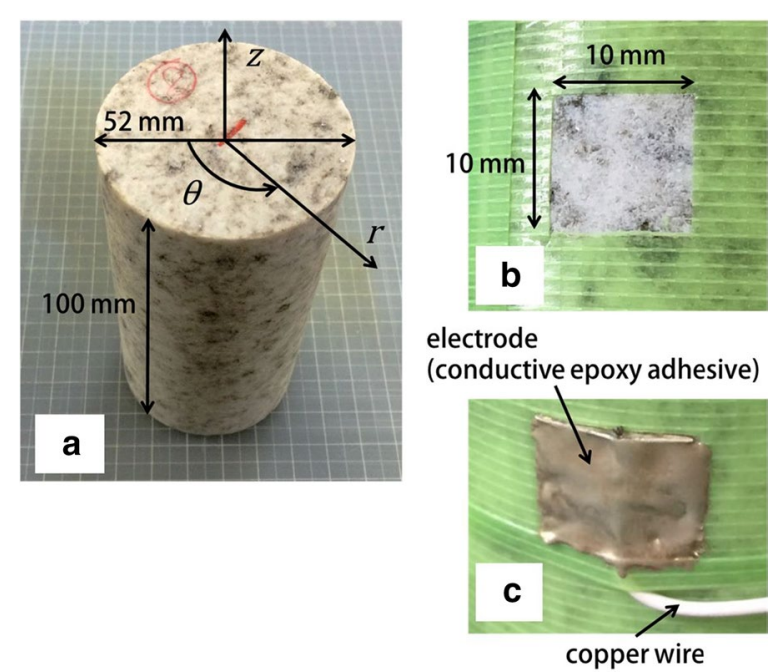

Fig. 2 Photographs of set-up for measurement of a granite sample. a The unpolished, cylindrical rock sample $(52 \mathrm{~mm}$ diameter, $100 \mathrm{~mm}$ length) overlaid with the dimensions $r, \theta$, and $z$ defining its coordinate axis. $\mathbf{b}$ The electrode attachment area as controlled by insulating masking tape. c Conductive epoxy adhesive attached to the rock surface as a high-conductivity electrode can be expected to have high adhesion and good conductivity, even on dry rock surfaces.

Before attaching the electrodes, the rock's cylindrical surface was masked by insulating masking tape, leaving gaps defining the electrode attachment area (Fig. 2b, c). This masking allowed precise control of the electrodes' positions. Copper wire was attached to the epoxy adhesive to connect the measurement instruments. Table 1 lists the physical properties of the conductive adhesive.

A small square electrode area of $100 \mathrm{~mm}^{2}$ was used in this test of our new measurement method. As the procedure was designed for future use in electrical tomography, the performance needs to be assessed using small electrodes.

\section{Current injection}

This study used two instruments to inject constant direct current depending on the experimental purposes. The first was an electrometer (Model 6514, Keithley, Cleveland, Ohio, US.). It was used in resistance measurement mode to inject direct constant current and measure the resulting voltage; resistance measurement is by two-terminal measurement. The measured resistance value is the sum of the sample resistance and contact resistance. The constant amount of injected direct current was set given the resistance range of the measured object (Table 2). The electrometer's maximum measurable resistance was $210 \mathrm{G} \Omega$. The experiments on the rock sample in "Stability and validity of measurements" section used an electrometer, because it was necessary to measure the

Table 1 Physical properties of conductive epoxy adhesive (Chemtronics CW2400)

\begin{tabular}{ll}
\hline Operating temperature range & -91 to $100^{\circ} \mathrm{C}$ \\
Volume resistivity & $<10 \mu \Omega \mathrm{m}$ \\
Main component & Epoxy resin, silver, and hardener \\
Curing times & $5-10$ min from $65-121^{\circ} \mathrm{C}, 4 \mathrm{~h}$ at \\
& or above $25^{\circ} \mathrm{C}$ \\
\hline
\end{tabular}

Table 2 Accuracy specifications for resistance measurement by the electrometer (Keithley 6514)

\begin{tabular}{lll}
\hline Range $(\Omega)$ & Resolution $(\Omega)$ & $\begin{array}{l}\text { Direct } \\
\text { injection } \\
\text { current }(A)\end{array}$ \\
\hline $2 \times 10^{6}$ & $1 \times 10^{1}$ & $0.9 \times 10^{-6}$ \\
$2 \times 10^{7}$ & $1 \times 10^{2}$ & $0.9 \times 10^{-6}$ \\
$2 \times 10^{8}$ & $1 \times 10^{3}$ & $0.9 \times 10^{-6}$ \\
$2 \times 10^{9}$ & $1 \times 10^{4}$ & $0.9 \times 10^{-9}$ \\
$2 \times 10^{10}$ & $1 \times 10^{5}$ & $0.9 \times 10^{-9}$ \\
$2 \times 10^{11}$ & $1 \times 10^{6}$ & $0.9 \times 10^{-9}$ \\
\hline
\end{tabular}


two-terminal resistance, to separate out contact and sample resistance, and to evaluate the dependence of the measurement environment on the sample and contact resistance.

The other instrument to inject constant direct current was a direct-current voltage/current source monitor (Model 6243, ADC; Saitama, Japan), which was able to set the amount of injected direct current to an arbitrarily large value up to $2 \mathrm{~A}$ at up to $32 \mathrm{~V}$. Its maximum applied voltage was $110 \mathrm{~V}$, and the minimum resolution of the injected current was $1 \mathrm{nA}$. The experiments on plastic samples "Stability and validity of measurements" and rock "Electrical measurements using an electrode array" used this device because they required the greatest injected current possible and increased signal-to-noise ratio in order to facilitate the measurement of potential distribution. The measurement of potential distribution required measurement of not only the potential near the current electrodes but also the low potential values far from them. Therefore, increased current was necessary to amplify the potential, and this required an instrument capable of setting the amount of injected current. The amount of injected current was measured by the ammeter of a multimeter (Model 3458A, Keysight; Santa Rosa, California, USA) with $1 \mathrm{pA}$ resolution.

\section{Voltage measurement}

Voltage measurement was with an electrometer (Model 6514, Keithley, Cleveland, Ohio, USA) set to voltage measurement mode. This instrument was also used for differential measurements. Its negative terminal was shorted with the negative terminal of the current source. In voltage measurement mode, the maximum input resistance is $200 \mathrm{~T} \Omega$, and insulation resistance between the negative terminal and the chassis ground is $10 \mathrm{G} \Omega$.

\section{Noise reduction}

We electrically isolated the shorted negative terminal from the chassis ground to prevent the influence of ground noise. Each measuring instrument was connected to the power supply through the transformer to prevent noise from the outlet. In all the resistance and voltage measurements, guarding reduced leakage current.

\section{Measurement environment}

Figure 3 shows the layout of the laboratory. The temperature in the laboratory was kept at $30{ }^{\circ} \mathrm{C}$ by an air conditioner during all measurements. Relative humidity was controlled with a dehumidifier (Model DM-10; Nakatomi, Nagano, Japan) capable of setting humidity in the range $30-90 \%$ in $5 \%$ steps and a humidifier (Model HD-152, Dainichi, Niigata, Japan) programmable to $60 \%$,

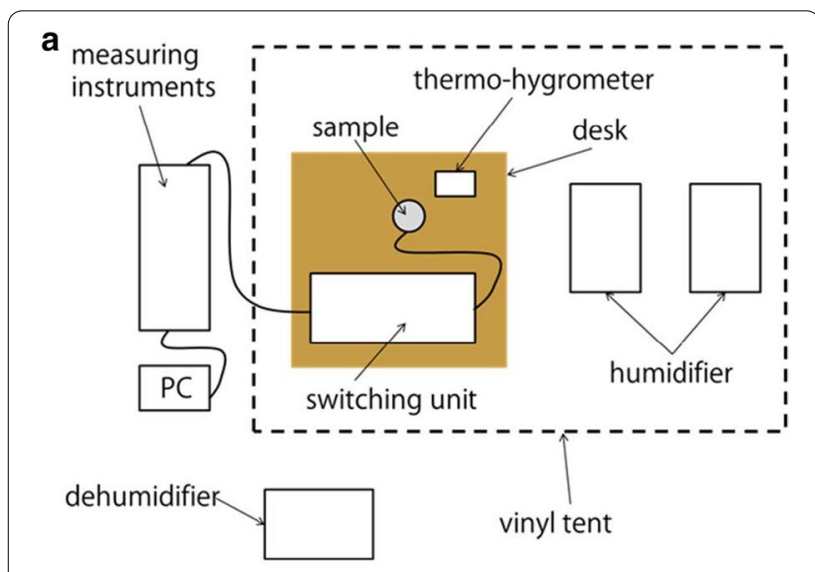

b

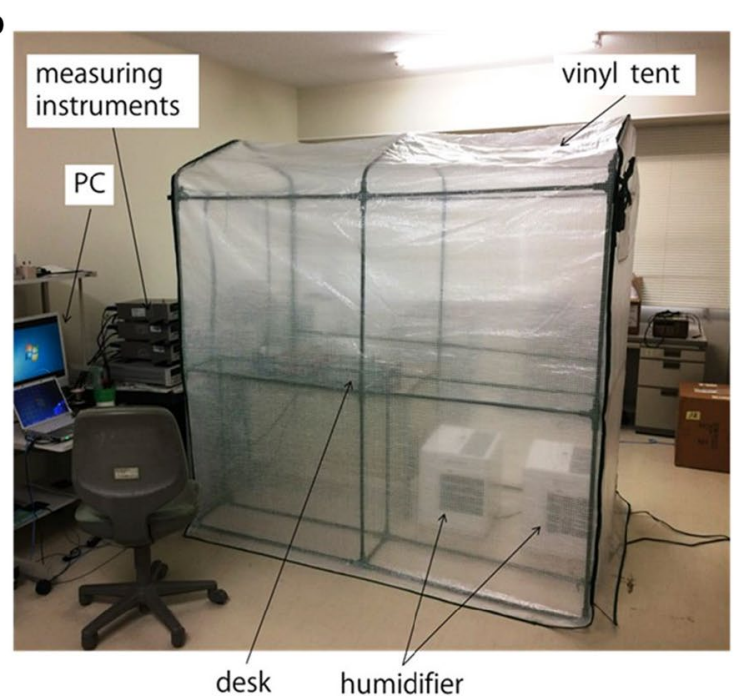

Fig. 3 a Layout of measurement instrumentation and $\mathbf{b}$ photograph of the measurement system in the laboratory

$70 \%$, or $80 \%$ humidity. The humidity condition was maintained throughout the laboratory, except the very high humidity condition, which was maintained only inside the vinyl tent. Temperature and relative humidity were recorded hourly by a temperature and humidity logger (Model LR5001, Hioki, Ueda, Japan) placed near the granite sample. The granite sample, thermo-hygrometer, and switching unit were placed on the same desk, while the granite sample was placed on insulating rubber plates to prevent leakage current. The granite sample subjected to analyses is shown in Fig. 2a.

Terminal switching was performed by the switch unit (HP34970A, Hewlett-Packard; Palo Alto, California, USA). All measurements were controlled by LabVIEW software (National Instruments, 15.0). Operators did not enter the laboratory during the measurement period. 


\section{Stability and validity of measurements}

This section evaluates the stability and validity of the proposed measurement procedure.

We evaluated the stability of the procedure in terms of the stabilities of resistances measured between the current electrodes, $R_{\text {measured }}$, the potential difference measured between the potential electrodes, $V_{\mathrm{P}_{1}}-V_{\mathrm{P}_{2}}$, and the measured current, $I$. To evaluate the stabilities, we set six levels of relative humidity and constant temperature. At each level, we checked the stability through six sequences of repeated measurements.

In addition, we checked the adhesion performance through observations of the contact surface, because strong adhesion between electrodes and the sample is important in our experimental set-up.

\section{Stability evaluation}

\section{Configuration of electrodes}

Figure 4 shows the granite sample's cylindrical surface and the electrode arrangement with the measurement instruments. We observed the contact surface by microfocus X-ray computed tomography $(\mathrm{CT})$ to confirm the contact state of the electrodes. The CT results in Fig. 5 show that the electrodes were well attached, despite the roughness of the surface, thus demonstrating the strong adhesion achieved by the proposed method.

\section{Data sampling with humidity and temperature setting}

$R_{\text {measured }}, I$, and $V_{\mathrm{P}_{1}}-V_{\mathrm{P}_{2}}$, were measured for $600 \mathrm{~s}$ in each measurement, which was repeated multiple times. Sampling was conducted every $1 \mathrm{~s}$. To eliminate the charge between the current electrode and granite surface, all terminals were shorted after each $600 \mathrm{~s}$ measurement. The discharge time for each repeat measurement was set to $2 \mathrm{~h}$ during resistance measurements in the G $\Omega$ range. Resistance measurements in the $M \Omega$ range used a longer discharge time of $6 \mathrm{~h}$ due to the greater injected current amount (Table 2).

Six sequences of repeated measurements gathered data for $R_{\text {measured }}, I$, and $V_{\mathrm{P}_{1}}-V_{\mathrm{P}_{2}}$. One sequence is considered as a group of repeated measurement data performed at fixed humidity and temperature. The six sequences considered relative humidity at six set values $(40 \%, 50 \%, 60 \%$, $70 \%, 80 \%$, and $90 \%)$ and constant temperature $\left(30{ }^{\circ} \mathrm{C}\right)$.

\section{Procedure for separating sample and contact resistance from measured resistance}

The $R_{\text {measured }}$ obtained by two-terminal measurement includes the sample resistance between the current elec-

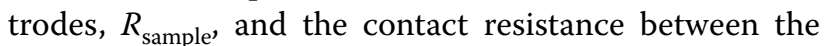
electrodes, $R_{\text {contact }}$. We separate $R_{\text {measured }}$ into $R_{\text {sample }}$ and $R_{\text {contact }}$ by the following procedure.

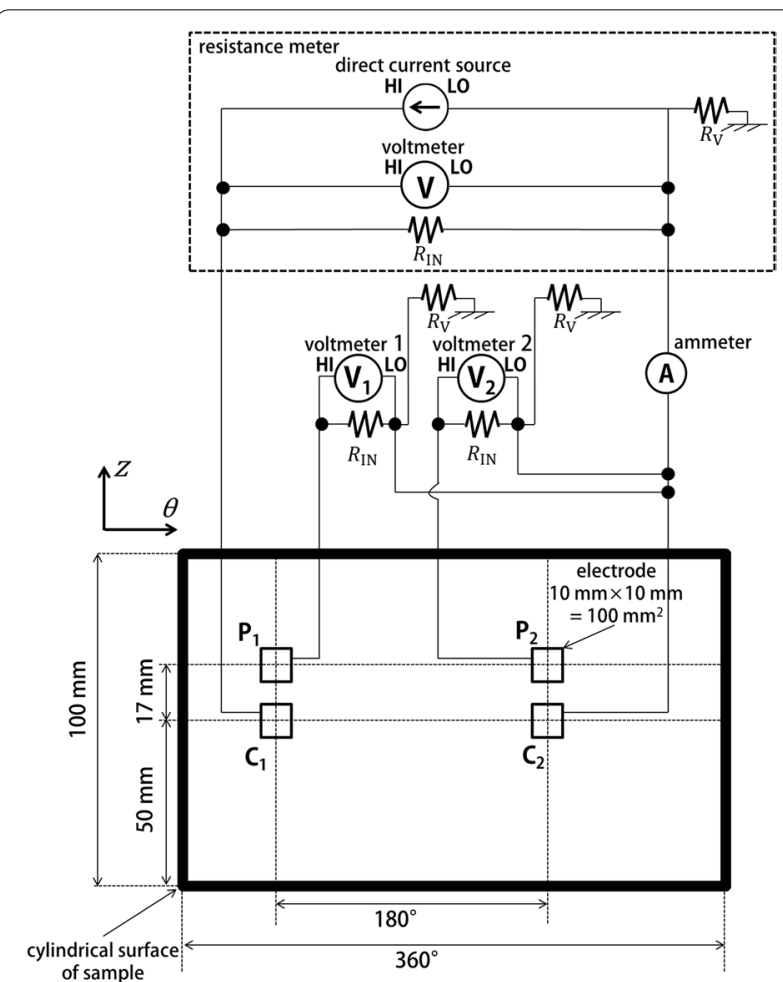

Fig. 4 Measurement scheme. $z$ and $\theta$ are coordinates defined in Fig. 2a. The dotted square is a resistance meter, $R_{\mathbb{N}}$ is input resistance, $R_{\mathrm{V}}$ is insulation resistance between the negative terminal and chassis ground, $\mathrm{HI}$ labels positive terminals, $\mathrm{LO}$ labels negative terminals, $C_{1}$ and $C_{2}$ are current electrodes, and $P_{1}$ and $P_{2}$ are potential electrodes. The electrometer (Model 6514, Keithley, Cleveland, Ohio, US.) in resistance measurement mode injects known direct constant current, measures the voltage caused by injected current, and obtains resistance. An ammeter (Model 3458A, Keysight; Santa Rosa, California, USA) was placed in order to monitor the amount of injected current. Electrometers (Model 6514, Keithley, Cleveland, Ohio, US.) with $R_{\mathbb{I N}}=200 \mathrm{~T} \Omega$ acted as the resistance meter and the voltmeter

First, we determine the sample resistivity, $\rho_{\text {sample }}$, using $I$ and $V_{\mathrm{P}_{1}}-V_{\mathrm{P}_{2}}$. We assume that the sample is homogeneous and isotropic. When the current $I$ is injected through the current electrode, the potential difference $V_{\mathrm{P}_{1}}-V_{\mathrm{P}_{2}}$ is expressed as

$$
V_{\mathrm{P}_{1}}-V_{\mathrm{P}_{2}}=\rho_{\text {sample }} K\left(\mathrm{P}_{1}, \mathrm{P}_{2}\right) I,
$$

where $K$ is a function of the positions of a pair of potential electrodes. In general, the function $K$ is determined either by solving the boundary value problem for the potential distribution or experimentally for a given shape of the conductive medium and the given positions of current electrodes. This work determines $K$ using a numerical calculation code developed by Suzuki et al. (2017), which is a modified version of the classical procedure 

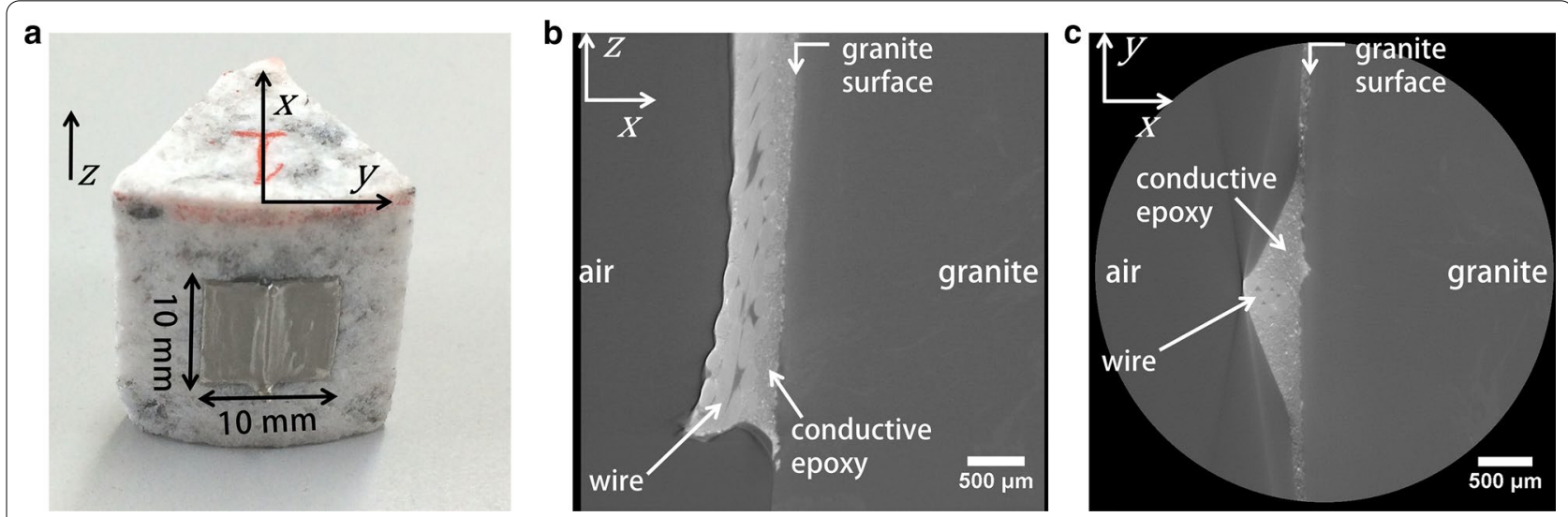

Fig. 5 Microstructures of the contact surface observed by micro-focus X-ray computed tomography (CT). a Sample photograph showing the 100 $\mathrm{mm}^{2}$ electrode. CT images of the $\mathbf{b} x-z$ and $\mathbf{c} x-y$ planes; the pixel size is approximately $4 \mu \mathrm{m}$, and the scale bar in each image is $500 \mu \mathrm{m}$. Black in the $\mathrm{CT}$ images represents areas of $\mathrm{X}$-ray transmission; the white areas are opaque to $\mathrm{X}$-rays. Here, black represents mainly air, dark grey is mainly granite, and light grey is the conductive epoxy adhesive and wires

proposed by Dey and Morrison (1979) for cylindrical coordinates.

Here, the unknown $\rho_{\text {sample }}$ is determined to fit the measured $I, V_{\mathrm{P}_{1}}-V_{\mathrm{P}_{2}}$, and the determined $K$. Once $\rho_{\text {sample }}$ is found, the potential difference between current electrodes $V_{\mathrm{C}_{1}}-V_{\mathrm{C}_{2}}$ is calculated:

$$
V_{\mathrm{C}_{1}}-V_{\mathrm{C}_{2}}=\rho_{\text {sample }} K\left(\mathrm{C}_{1}, \mathrm{C}_{2}\right) I \text {, }
$$

which implies that the resistance between the current electrodes, $R_{\text {sample }}$ is given by

$$
R_{\text {sample }}=\frac{V_{\mathrm{C}_{1}}-V_{\mathrm{C}_{2}}}{I}=\rho_{\text {sample }} K\left(\mathrm{C}_{1}, \mathrm{C}_{2}\right) \text {. }
$$

The contact resistance $R_{\text {contact }}$ can then be determined. The resistance $R_{\text {measured }}$ obtained by the two-terminal measurements is not the same as $R_{\text {sample }}$ but the sum of $R_{\text {contact }}$ and $R_{\text {sample }}$. Note that the contact resistance $R_{\text {con- }}$ tact affects neither the calculated $V_{\mathrm{C}_{1}}-V_{\mathrm{C}_{2}}$ nor $I$; thus, $R_{\text {contact }}$ does not affect $R_{\text {sample }}$ in Eq. 3 . Assuming that the contact resistances $R_{\text {contact }}$ at both current electrodes are the same, $R_{\text {contact }}$ is determined by

$$
R_{\text {measured }}=R_{\text {sample }}+2 R_{\text {contact }} \text {. }
$$

This procedure for separating sample and contact resistance from measured resistance is shown in Fig. 6 . Note that the electrode arrangement shown is that adopted in this study, and our procedure can separate sample and contact resistance from measured resistance in any electrode arrangement.

\section{Inspection and processing of time-series data}

The stability of the measured resistance, current, and potential difference was assessed using time series of the data of the type depicted in Fig. 7 for $40 \%$ relative humidity and $30{ }^{\circ} \mathrm{C}$. The time-series data show transient phenomena. The current recorded for about $1 \mathrm{~min}$ after the start of measurement was larger than that specified by the resistance meter $(0.9 \mathrm{nA}$; Table 2$)$. This large current meant that it took several tens of seconds for the measured resistance and potential difference to stabilise.

The large current at the start of measurement was interpreted as an inrush current. The increase of observed resistance after the current had settled probably corresponds to charging. Both of these effects shifted the measured resistance to higher values than their actual values. Therefore, it is reasonable to adopt the minimum value observed in each $600 \mathrm{~s}$ of resistance data, which likely includes the smallest effects of charging and inrush current.

On the other hand, after the inrush current, the current and potential difference became almost constant in the time-series data, indicating little polarisation of the entire sample. For standardised selection, the current and potential difference at the time of minimum resistance were chosen, as indicated by the dashed line in Fig. 7 .

\section{Stability of repeated measurements}

Table 3 shows the stability of temperature, relative humidity, and absolute humidity in the six sequences. In each case, temperature varied by at most approximately $0.5{ }^{\circ} \mathrm{C}$, and humidity varied by at most approximately $3 \%$. 


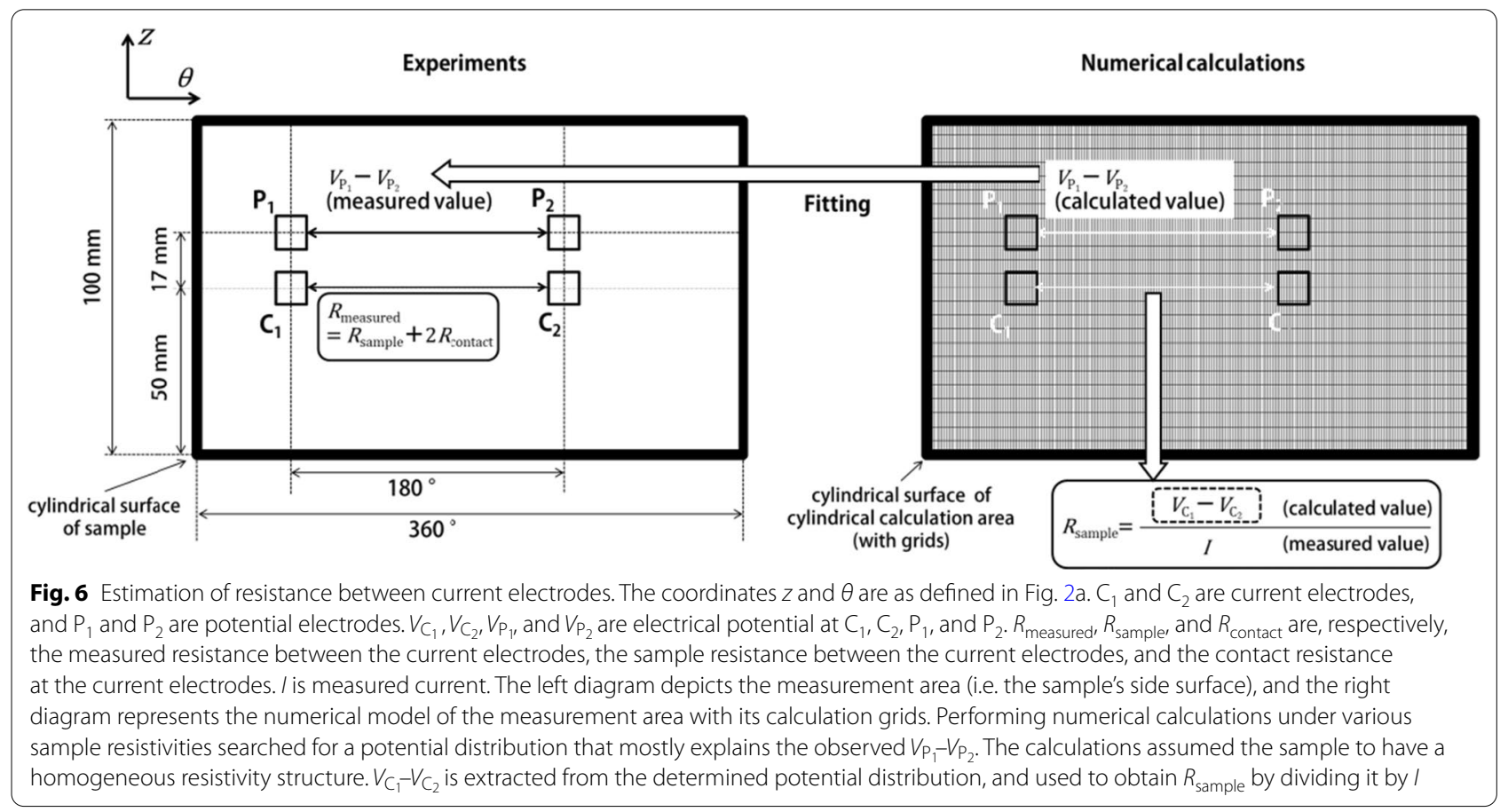

The measured temperature and humidity were far more stable than those of the outside air.

Figure 8 and Table 4 show the results of repeated measurements in the six sequences and their statistical comparison, respectively. Figure 8a confirms that the specified current of $0.9 \mathrm{nA}$ was injected correctly without leakage current. Figure $8 \mathrm{~b}$, c shows the high stability and reproducibility of measurement. Because the current flowing through the ammeter is the sum of the injected current and the noise current, the observed current is larger than the specified current of $0.9 \mathrm{nA}$. We defined the fluctuation at each sequence as the standard deviation of all measurements in each sequence. The potential differences and resistances considerably decreased with increasing absolute humidity, with measured resistance being especially sensitive to absolute humidity even within each sequence.

The stability of the four-terminal measurement was assessed using standard deviations of the potential difference between potential electrodes $\mathrm{P}_{1}-\mathrm{P}_{2}$ and of the intensity of the injected current. That of the two-terminal measurement was assessed using the standard deviation of the resistance measured at each humidity setting. Table 4 lists these statistics, together with averaged values of corresponding quantities. From the listed values (with a few outliers manually excluded) and the results of forward modelling, we estimated $\rho_{\text {sample }}$ as listed in Table 5 by means of the procedure explained in "Procedure for separating sample and contact resistance from measured resistance" section. This estimation excluded negative values of the potential difference between $P_{1}$ and $P_{2}$ that appeared at humidity settings of $70 \%$ and $80 \%$, because potential differences between these electrodes must be positive, and thus a negative value implies some problem with the measurement. At humidity settings of $70 \%$ and $80 \%$, the voltage signal generated by the injected current becomes very small, because $R_{\text {measured }}$ approaches the lower limit of the $G \Omega$ range of the electrometer (Keithley 6514). Table 2 shows the instrument's injection current to be $1 \mathrm{nA}$ in the $G \Omega$ range and $1 \mu \mathrm{A}$ in the $\mathrm{M} \Omega$ range. The appropriate range must be selected to prevent hazardous high voltage injection. Therefore, at humidity settings of $70 \%$ and $80 \%$, the signal to be observed was so small that signal noise momentarily caused a very small negative value. The standard deviations of estimated resistivity were small compared with their mean values, indicating the stability of the obtained $\rho_{\text {sample }}$. Note that the order of obtained resistivity (between $10^{5}$ and $10^{6} \Omega \mathrm{m}$ ) at humidity between 50 and $80 \%$ was consistent with the bulk resistivity values of dry granodiorite reported in Chiba and Kumada (1994).

\section{Estimation of resistance between current electrodes and contact resistance}

Figure 9 shows estimated values for $R_{\text {sample }}$ and $R_{\text {contact }}$. Not only $R_{\text {sample }}$, but also $R_{\text {contact }}$ greatly decreased with increasing absolute humidity, further showing the necessity of controlling humidity in the laboratory for measurements of dry rock resistance. 

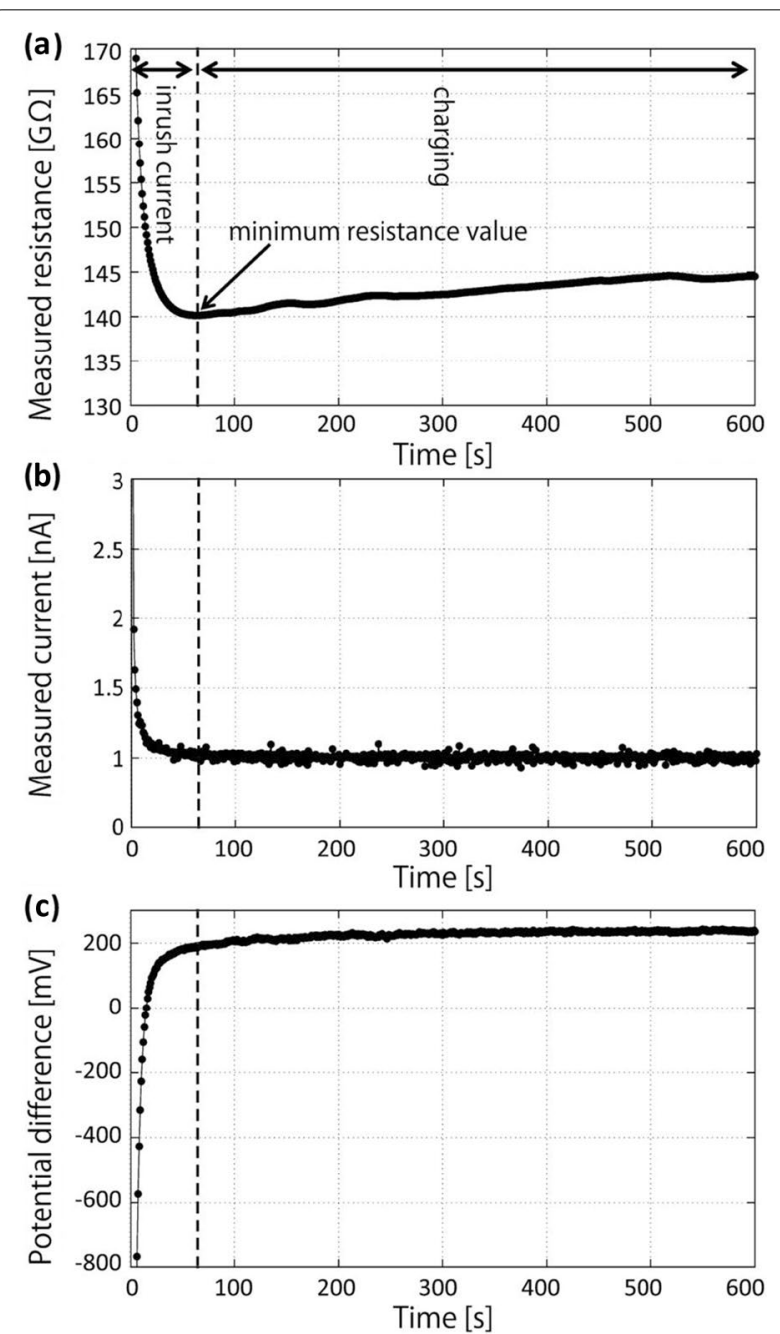

Fig. 7 Representative time-series data for resistance, current, and potential difference. The results are those measured for $600 \mathrm{~s}$ at $40 \%$ relative humidity and $30{ }^{\circ} \mathrm{C}$ using the measurement layout in Fig. 3 . a Resistance between $C_{1}$ and $C_{2}$ measured by a resistance meter. $\mathbf{b}$ Current measured by an ammeter. $\mathbf{c}$ Potential difference between $\mathrm{P}_{1}$ and $P_{2}$. The injected current took several tens of seconds to stabilise after measurement started. It was initially larger than the specified current used by the resistance meter to measure resistance in the $\mathrm{G} \Omega$ range, and was interpreted as inrush current. This inrush current caused the resistance also to take several tens of seconds to stabilise, after which resistance increased. This was interpreted as charging. The minimum in the resistance data for $600 \mathrm{~s}$ is therefore considered the most representative value, because the effects of inrush current and charging are likely smallest. Current and potential difference were taken as their values at the time when resistance was lowest, as indicated by the dashed line

$R_{\text {contact }}$ was much larger than $R_{\text {sample, }}$ and accounted for most of each $R_{\text {measured }}$ value in Fig. 8c. This suggests that the area of the current path present on the electrode bonding surface is small with respect to the apparent electrode size: current appears to flow between the rock
Table 3 Stability of temperature and relative humidity in each sequence

\begin{tabular}{lllll}
\hline $\begin{array}{l}\text { Humidity } \\
\text { setting } \\
(\%)\end{array}$ & \multicolumn{2}{l}{ Mean and standard deviation } & $\begin{array}{l}\text { Number of } \\
\text { recordings }\end{array}$ \\
\cline { 2 - 4 } & $\begin{array}{l}\text { Temperature } \\
\left({ }^{\circ} \mathbf{C}\right)\end{array}$ & $\begin{array}{l}\text { Humidity } \\
(\%)\end{array}$ & $\begin{array}{l}\text { Absolute } \\
\text { humidity (g/ } \\
\mathbf{m}^{\mathbf{3}} \text { ) }\end{array}$ \\
\hline 40 & $29.4 \pm 0.7$ & $40.6 \pm 2.1$ & $11.9 \pm 0.6$ & 136 \\
50 & $29.3 \pm 0.3$ & $51.1 \pm 2.5$ & $15.0 \pm 0.6$ & 67 \\
60 & $29.3 \pm 0.3$ & $61.4 \pm 1.6$ & $17.9 \pm 0.3$ & 87 \\
70 & $29.4 \pm 0.4$ & $69.2 \pm 2.5$ & $20.3 \pm 0.5$ & 80 \\
80 & $29.5 \pm 0.2$ & $79.9 \pm 2.5$ & $23.6 \pm 0.7$ & 190 \\
90 & $30.3 \pm 0.3$ & $89.2 \pm 2.9$ & $27.5 \pm 0.8$ & 117 \\
\hline
\end{tabular}

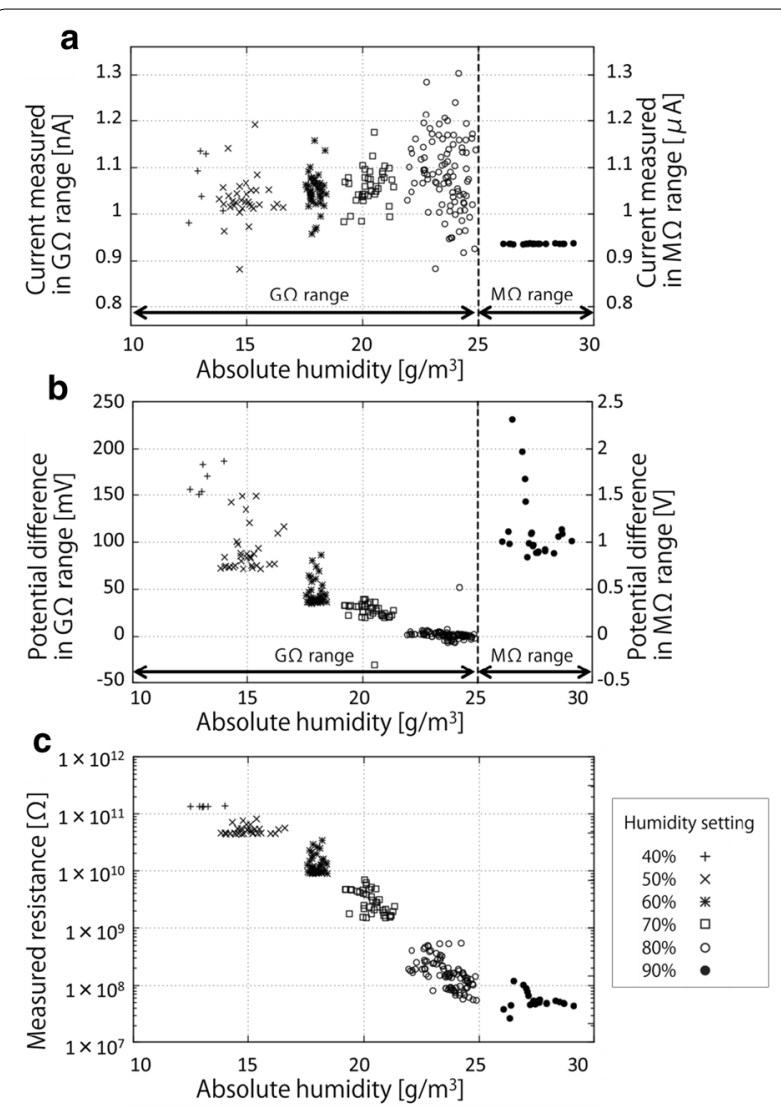

Fig. 8 Current, potential difference, and resistance with respect to absolute humidity. a Current measured by ammeter and $\mathbf{b}$ measured potential difference between $P_{1}$ and $P_{2}$ as a function of the absolute humidity. $\mathbf{c}$ Measured resistance between $C_{1}$ and $C_{2}$ as a function of the absolute humidity in log scale. Measurements were repeated in six sequences of relative humidity $(40 \%, 50 \%, 60 \%, 70 \%, 80 \%$, and $90 \%)$ under constant temperature $\left(30^{\circ} \mathrm{C}\right)$, with the symbols indicating the measurement sequence. The injected current amount depended on the resistance measurement range (Table 2) 
Table 4 Statistical comparison of repeated measurements

\begin{tabular}{|c|c|c|c|c|}
\hline \multirow[t]{3}{*}{ Humidity setting (\%) } & \multicolumn{3}{|c|}{ Mean and standard deviation } & \multirow{3}{*}{$\begin{array}{l}\text { Number of } \\
\text { measurements }\end{array}$} \\
\hline & \multicolumn{2}{|c|}{ Four-terminal measurement } & \multirow{2}{*}{$\begin{array}{l}\text { Two-terminal measurement } \\
\text { Resistance }\left(R_{\text {measured }}\right)(\Omega)\end{array}$} & \\
\hline & Current (nA) & Potential difference (mV) & & \\
\hline 40 & $1.06 \pm 0.06$ & $166.9 \pm 14.4$ & $(1.36 \pm 0.02) \times 10^{11}$ & 6 \\
\hline 50 & $1.03 \pm 0.05$ & $91.0 \pm 23.2$ & $(5.27 \pm 0.97) \times 10^{10}$ & 33 \\
\hline 60 & $1.05 \pm 0.04$ & $45.4 \pm 12.8$ & $(1.36 \pm 0.62) \times 10^{10}$ & 43 \\
\hline 70 & $1.06 \pm 0.04$ & $26.8 \pm 11.0$ & $(3.20 \pm 1.48) \times 10^{9}$ & 39 \\
\hline 80 & $1.09 \pm 0.08$ & $1.62 \pm 5.94$ & $(1.86 \pm 1.20) \times 10^{8}$ & 94 \\
\hline 90 & $937 \pm 1$ & $1152 \pm 368$ & $(5.53 \pm 2.25) \times 10^{7}$ & 24 \\
\hline
\end{tabular}

Table 5 Statistical comparison of estimated resistivity in repeated measurements

\begin{tabular}{|c|c|c|c|}
\hline \multirow{2}{*}{$\begin{array}{l}\text { Humidity } \\
\text { setting (\%) }\end{array}$} & \multicolumn{2}{|c|}{ Mean and standard deviation } & \multirow{2}{*}{$\begin{array}{l}\text { Number of } \\
\text { estimated } \\
\text { values }\end{array}$} \\
\hline & $\begin{array}{l}\text { Absolute } \\
\text { humidity (g/ } \\
\left.\mathrm{m}^{3}\right)\end{array}$ & $\begin{array}{l}\text { Estimated resistivity } \\
(\Omega \mathrm{m})\end{array}$ & \\
\hline 40 & $11.9 \pm 0.6$ & $(1.0 \pm 0.1) \times 10^{7}$ & 6 \\
\hline 50 & $15.0 \pm 0.6$ & $(5.7 \pm 1.4) \times 10^{6}$ & 33 \\
\hline 60 & $17.9 \pm 0.3$ & $(2.7 \pm 0.6) \times 10^{6}$ & 41 \\
\hline 70 & $20.3 \pm 0.5$ & $(1.7 \pm 0.4) \times 10^{6}$ & 38 \\
\hline 80 & $23.6 \pm 0.7$ & $(1.4 \pm 1.0) \times 10^{5}$ & 68 \\
\hline 90 & $27.5 \pm 0.8$ & $(7.6 \pm 2.0) \times 10^{4}$ & 23 \\
\hline
\end{tabular}

Any data outside the range of (mean) $\pm 3 \times$ (standard deviation) were removed as outliers, and the statistics were recalculated

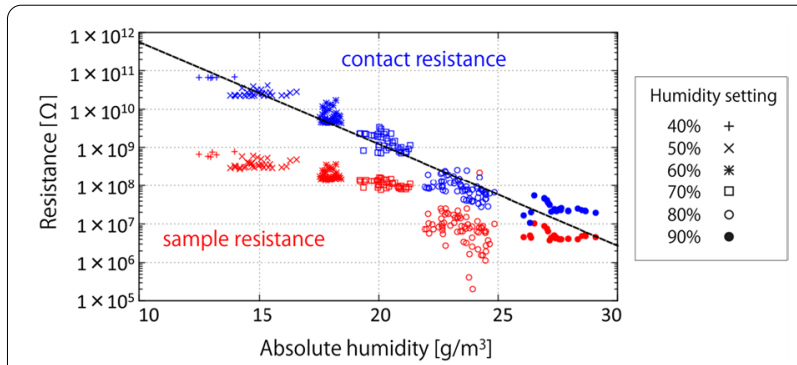

Fig. 9 Estimated contact resistance and sample resistance with respect to absolute humidity. Resistances between current electrodes $C_{1}$ and $C_{2}$ are plotted as a function of the absolute humidity in log scale. The dashed line represents exponential fitting results, and the symbols indicate the measurement sequence. Sample resistance was estimated numerically from the measured current and potential difference values in Fig. 8a, b. Contact resistance is half of the value obtained by subtracting the estimated sample resistance from the measured resistance value in Fig. $8 \mathrm{c}$ surface and the electrode only through part of the contact area observed by CT scanning.

Changes in $R_{\text {sample }}$ and $\rho_{\text {sample }}$ with changes in humidity were attributed to moisture absorption by the sample. Alvarez (1973) and Okuyama (1973) reported that moisture greatly changes the resistance and resistivity of dry rock. Alvarez (1973) concluded that the adsorption of water molecules to minerals changed the resistance of rock samples, as also suggested by the present results.

The resistivity obtained here is that of a rock considered an aggregate of minerals. Although a surface water film on the nm scale or thinner can also affect the resistivity, surface conduction in the electric double layer is considered negligible here, because our experiments were performed at low humidity. Previous studies (e.g., Gee et al. 1990; Mazzoco and Wayner 1999; Pashley and Kitchener 1979) have found the water film on a quartz surface to be several $\mathrm{nm}$ thick at around $95 \%$ relative humidity. As our experiments were performed at lower humidity conditions, the water film thickness in our measurements was considered to be several $\mathrm{nm}$ or less. In this case, unless the ion concentration of water in the atmosphere is extremely high, it is not necessary to consider the effect of the electric double layer. The observed high resistivity and resistance of our rock sample is consistent with this proposition.

We interpret the changes in $R_{\text {contact }}$ to reflect atmospheric moisture penetrating the contact surface and filling minute gaps between the electrode and rock surface, thus increasing the contact points. It is reasonable to assume that moisture adsorption would occur even at the contact surface. Linear fitting to the estimated results (Fig. 9) is used to investigate whether the relationship between absolute humidity and $R_{\text {contact }}$ can be expressed by a simple function. The estimated $R_{\text {contact }}$ appears mostly consistent with the fitting results, which implies the presence of an exponential relationship between 
absolute humidity and $R_{\text {contact }}$. The observed exponential relationship suggests that the number of contact points on the contact surface changes exponentially with changes in humidity. The fitting function assumes an exponential relationship for $R_{\text {contact }}=C 10^{a H_{A}}$, where $C$ and $a$ are constants, and $H_{\mathrm{A}}$ is absolute humidity.

\section{Validity evaluation}

To check the validity of the procedure for estimating the sample resistivity described in "Procedure for separating sample and contact resistance from measured resistance" section, we applied the method to plastic samples of known resistivity. We processed each type of plastic into a cylinder and a thin disk. The resistivity of the thin disk was determined by bulk resistivity measurement and that of the cylinder was determined by our method. The obtained resistivity values, together with the supplier's nominal resistivity value, were compared.

We used two types of plastics with different resistivity, one low (MC501CD R2, Mitsubishi Chemical Advanced Materials, Tokyo, Japan) and the other high (MC500AS R11, Mitsubishi Chemical Advanced Materials, Tokyo, Japan). Figure 10 shows photographs of the samples. Their nominal resistivity values are $10^{\circ}$ to $10^{2} \Omega \mathrm{m}$ and $10^{8}$ to $10^{10} \Omega \mathrm{m}$, respectively (Mitsubishi Chemical Advanced Material 2020a; b). Each was cut into a cylinder and thin disk (Fig. 10a1, a2, b1, and b2). For the thin disk, current electrodes made of conductive epoxy were attached to both ends and potential electrodes made of wire were attached to the side surface (Fig. 10a3, b3). This bulk resistivity measurement set-up is the same as that of Collet (1959) and Chiba and Kumada (1994). On the other hand, each cylinder had multiple small electrodes attached to its side surface for measurement by our proposed procedure. Figure 11 shows the side surface of the plastic cylinder and the electrode arrangement with the measurement instruments. This set-up was the same as that for the rock sample.

The resistivities of CD R2 and AS R11 were determined by bulk resistivity measurement to be $2.48 \Omega \mathrm{m}$ and $1.50 \times 10^{7} \Omega \mathrm{m}$, respectively. Tables 6 and 7 list the results from our procedure. Results from both samples from both methods were generally consistent with each other and with the nominal values. The determined resistivity of AS R11 was an order of magnitude lower than the lower limit of the nominal range. The deviation was attributed to product error because values obtained by both measurement methods matched each other.

These results confirm that $\rho_{\text {sample }}$ can be correctly estimated by our procedure for both high- and low-resistivity samples, thus demonstrating the validity of our procedure. They also confirm that our method can correctly estimate $\rho_{\text {sample }}$, regardless of the electrode arrangement.
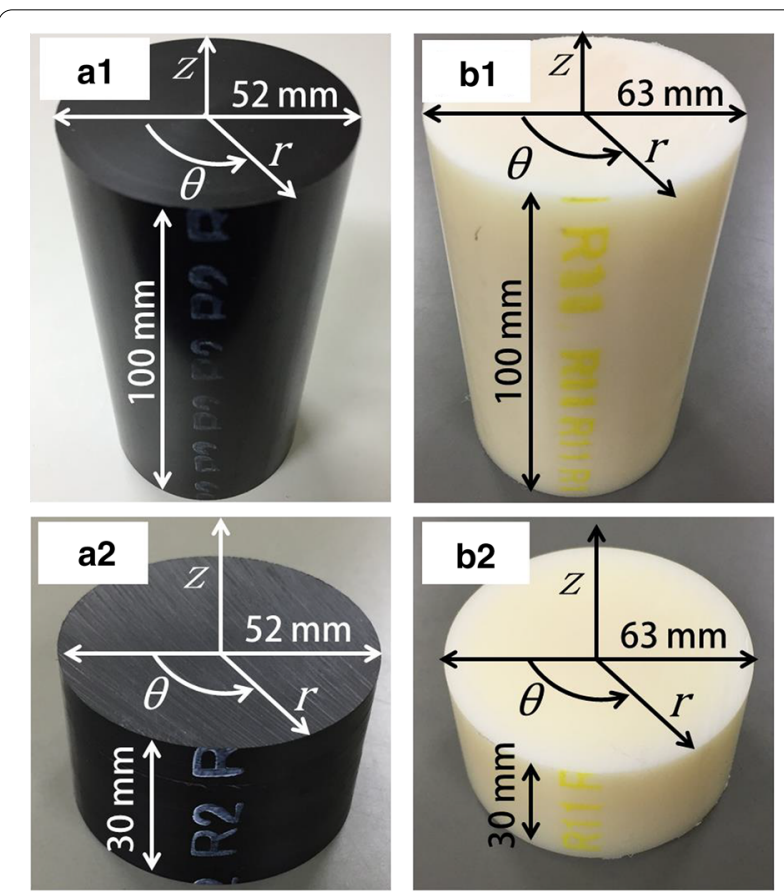

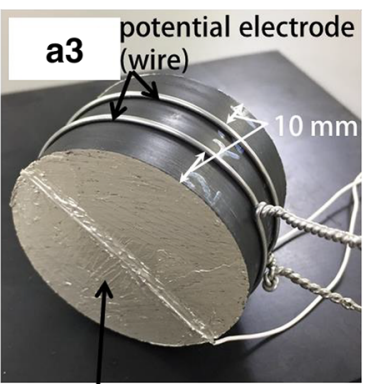

current electrode (conductive epoxy adhesive)

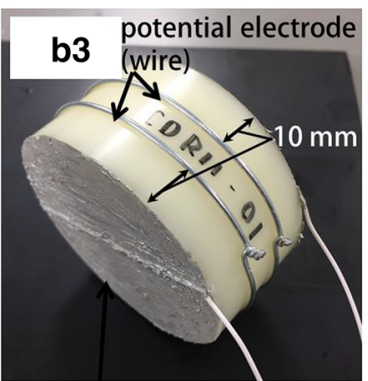

current electrode (conductive epoxy adhesive)
Fig. 10 Photographs of set-up for measurement of plastic samples overlaid with the dimensions $r, \theta$, and $z$ defining the coordinate axis. Top row: cylindrical plastic samples a1 MC501CD R2 (Mitsubishi Chemical Advanced Materials, Tokyo, Japan; 52 mm diameter, $100 \mathrm{~mm}$ length) and b1 MC500AS R11 (Mitsubishi Chemical Advanced Materials, Tokyo, Japan; $63 \mathrm{~mm}$ diameter, $100 \mathrm{~mm}$ length). Middle row: thin-disk plastic samples (52 mm diameter, 30 length) of a2 MC501CD R2 and b2 MC500AS R11. Bottom row: arrangement of wire potential electrodes around the thin-disk samples' side surface and conductive epoxy-adhesive current electrodes attached to their ends, a3 MC501CD R2 and b3 MC500AS R11

\section{Electrical measurements using an electrode array}

We performed electrical measurements on intact rock using many electrodes in a simple configuration as a first step towards electrical tomography measurements. A constant current was injected into the sample, and the resulting potential distribution on the sample's cylindrical surface was measured using an electrode array. Sample resistivity, $\rho_{\text {sample }}$, was determined using numerical 


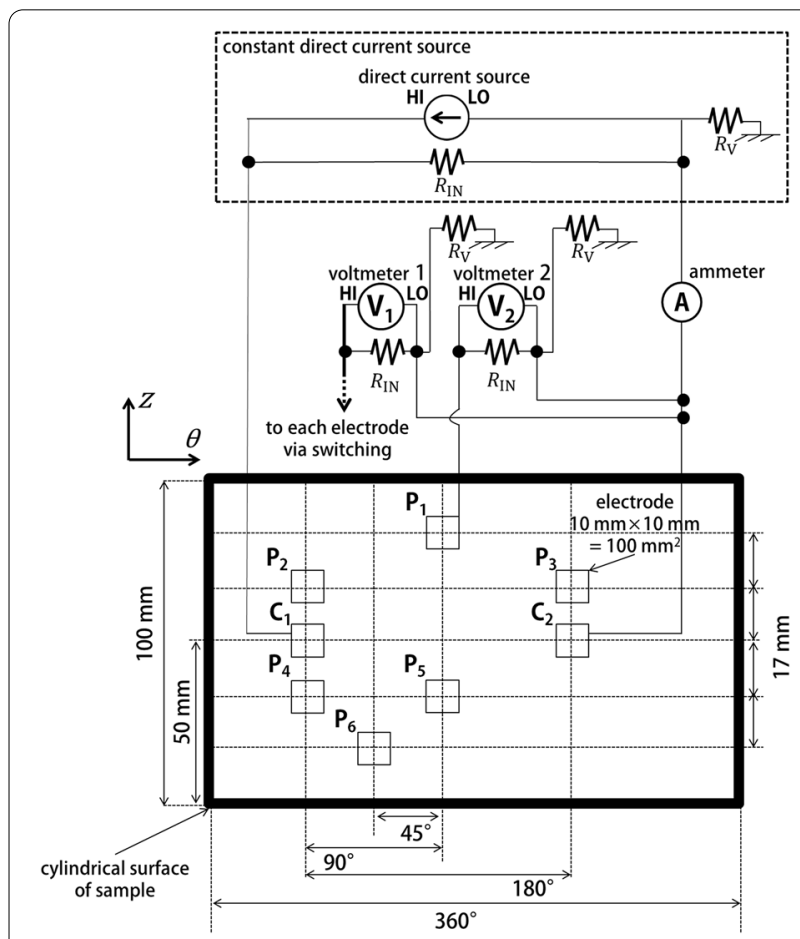

Fig. 11 A scheme of measurement for the cylindrical plastic samples. $z$ and $\theta$ are coordinates as defined in Fig. 10. $R_{\mathbb{N}}$ is input resistance, $R_{\mathrm{V}}$ is insulation resistance between the negative terminal and chassis ground, $\mathrm{HI}$ labels positive terminals, $\mathrm{LO}$ labels negative terminals, $\mathrm{C}_{1}$ and $\mathrm{C}_{2}$ are current electrodes, and $\mathrm{P}_{1}, \mathrm{P}_{2}, \mathrm{P}_{3}, \mathrm{P}_{4}, \mathrm{P}_{5}$, and $\mathrm{P}_{6}$ are potential electrodes. The DC source (Model 6243, ADC; Saitama, Japan) injected a known constant current. An ammeter (Model 3458A, Keysight; Santa Rosa, California, USA) monitored the injected current. Electrometers (Model 6514, Keithley, Cleveland, Ohio, US.) with $R_{\mathbb{N}}=200 \mathrm{~T} \Omega$ acted as the voltmeters calculation with the measured potential distribution and current.

\section{Measurement procedure Measurement set-up and procedure}

Figure 12 shows a photograph and a schematic diagram of the cylindrical surface of the granite sample on which 40 electrodes were arranged.

During measurement, a constant direct current was injected. The electrical potential of each potential electrode was measured via terminal switching. The positive terminal of $V_{1}$ was switched among the electrodes by the switch unit, whereas that of $V_{2}$ was fixed during measurement (Fig. 12b). Sampling was every 1 s. Electrical potential was measured for $600 \mathrm{~s}$ for each potential electrode. From this measurement, the potential distribution relative to the potential of the electrode connected to $V_{2}$ was obtained. The potential was ignored for the first $5400 \mathrm{~s}$ from the start of the current injection to avoid the effect of the inrush current. At the end of the sequence, we re-measured the potential at an electrode previously assessed at the beginning of the sequence to confirm that the potential did not temporally change. During the measurement, the temperature was kept at about $30{ }^{\circ} \mathrm{C}$, and the relative humidity was kept at about $70 \%$; therefore, the absolute humidity was kept at about $21.7 \mathrm{~g} / \mathrm{m}^{3}$.

\section{Procedure for determining sample resistivity using the measured potential distribution}

Based on the measured values of potential differences and current intensity, we determined $\rho_{\text {sample }}$ by the procedure

Table 6 Measurement results for the low-resistivity plastic sample (CD R2)

\begin{tabular}{lllll}
\hline Sample & $\begin{array}{l}\text { Pair of potential } \\
\text { electrodes }\end{array}$ & Mean and standard deviation & & $\begin{array}{l}\text { Estimated sample } \\
\text { resistivity }(\Omega \text { m })\end{array}$ \\
\cline { 3 - 4 } & Injected current $(\mathbf{m A})$ & Potential difference $(\mathrm{V})$ & 3.56 \\
\hline CD R2 & $P_{2}-P_{3}$ & $9.37 \pm 0.01$ & $0.517 \pm 0.001$ & 3.38 \\
& $P_{5}-P_{3}$ & $0.246 \pm 0.001$ & 3.56 \\
& $P_{4}-P_{1}$ & $0.259 \pm 0.001$ & 3.54 \\
\hline
\end{tabular}

Table 7 Measurement results for the high-resistivity plastic sample (AS R11)

\begin{tabular}{lllll}
\hline Sample & Pair of potential electrodes & Mean and standard deviation & & $\begin{array}{l}\text { Estimated } \\
\text { sample } \\
\text { resistivity }(\Omega \text { m) }\end{array}$ \\
\cline { 3 - 5 } & & Injected current $(\mathrm{nA})$ & Potential difference $(\mathrm{V})$ & $1.35 \times 10^{7}$ \\
\hline AS R11 & $29.5 \pm 0.1$ & $6.64 \pm 0.01$ & $1.28 \times 10^{7}$ \\
& $P_{2}-P_{3}$ & & $3.15 \pm 0.01$ & $1.33 \times 10^{7}$ \\
& $P_{5}-P_{3}$ & $3.28 \pm 0.01$ & $1.26 \times 10^{7}$ \\
\hline
\end{tabular}



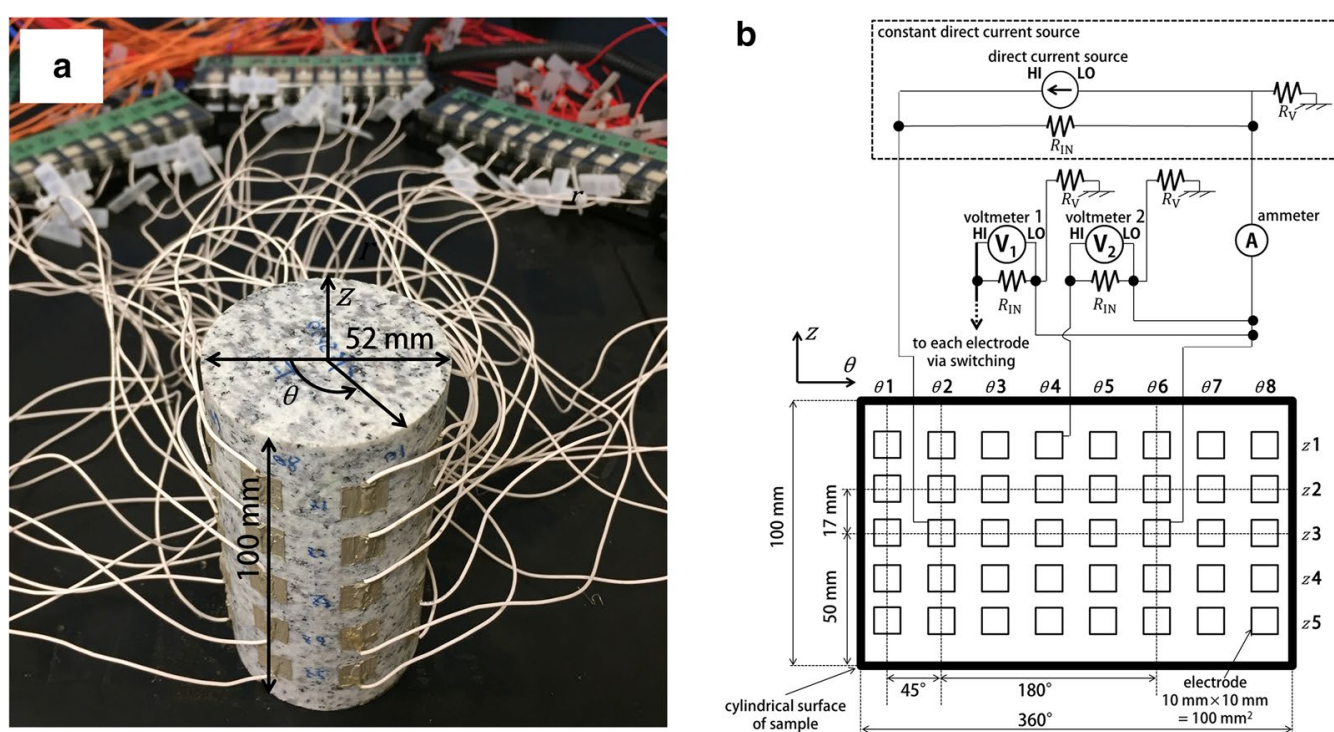

Fig. 12 Photograph and schematic diagram of the measurement set-up with an array of electrodes. a Cylindrical rock sample (52 mm diameter and $100 \mathrm{~mm}$ length) overlaid with the dimensions $r, \theta$, and $z$ defining its coordinate axes. Electrodes were attached to the cylindrical surface, and wires attached to electrodes provided a connection for measuring instruments. $\mathbf{b}$ Measurement scheme. $z$ and $\theta$ are coordinates defined in Fig. 10 a. The dotted square is a constant direct current source, $R_{\mathbb{N}}$ is input resistance, $R_{\mathrm{V}}$ is insulation resistance between the negative terminal and chassis ground, $\mathrm{HI}$ labels positive terminals, and LO labels negative terminals. The direct current source (Model 6243, ADC; Saitama, Japan) injected a known constant current. An ammeter (Model 3458A, Keysight; Santa Rosa, California, US.) monitored the amount of injected current. Electrometers (Model 6514, Keithley; Cleveland, Ohio, USA) with $R_{\mathbb{N}}=200 T \Omega$ acted as the voltmeters

described in "Procedure for separating sample and contact resistance from measured resistance" section. The stability test in "Stability of repeated measurements" and "Estimation of resistance between current electrodes and contact resistance" sections determined $\rho_{\text {sample }}$ and $R_{\text {sam- }}$ ple only using one potential difference between one pair of potential electrodes, but here $\rho_{\text {sample }}$ and $R_{\text {sample }}$ are determined from the potential distribution obtained from 38 electrodes. The modelling assumed the medium to have homogeneous and isotropic resistivity. Because the array measurement requires a relatively long time $(30,000 \mathrm{~s})$ for each sequence, the intensity of the injected current involved minor fluctuations, although we tried to maintain a constant current of $100 \mathrm{nA}$. The effect on this in the measured potential must be considered when comparing the results with those of numerical calculations with fixed current intensity. Therefore, we normalised the measured potential $V_{\text {uncorrected }}$ to $V_{\text {corrected }}=V_{\text {uncor- }}$ rected $\frac{(100 \mathrm{nA})}{I}$ and regarded it as the measured value. The value of $\rho_{\text {sample }}$ was determined so that it minimised the total difference between the measured and calculated potential at 38 potential electrodes, excluding the current electrodes by the following procedure. Here, Eq. (1) is equivalent to

$$
V_{i}-V_{(Z 1, \theta 4)}=\rho_{\text {sample }} K(i,(Z 1, \theta 4)) I+V_{\text {offset }} .
$$

$V_{i}$ is the electrical potential at the potential electrode at point $i$ measured via terminal switching. $V_{(Z 1, \theta 4)}$ is the electrical potential at the potential electrode at point $(Z 1, \theta 4)$. The constant $V_{\text {offset }}$ represents the difference between the actual and calculated potentials at the reference point $(Z 1, \theta 4) . K$ is determined as in "Procedure for separating sample and contact resistance from measured resistance" section. Two unknowns, $\rho_{\text {sample }}$ and $V_{\text {offset' }}$, are determined to fit the measured $I$ and $V_{i}-V_{(Z 1, \theta 4)}$ by least squares.

\section{Results and discussion}

\section{Inspection and processing of time-series data}

Figure 13a1-e1 shows the potentials obtained in each $z$-line indicated in Fig. 12a, b. The $V_{\text {offset }}$ determined in "Procedure for separating sample and contact resistance from measured resistance" section was removed from the measurement values shown in Fig. 13. At each point, data obtained at seven timings (i.e. 60, 100, 200, 300, 400, 500 , and $600 \mathrm{~s}$ ) in the $600 \mathrm{~s}$ time-series were plotted: their invariance confirms the stability of the time-series data after the inrush current; nevertheless, we used the average of the last $100 \mathrm{~s}$ of the $600 \mathrm{~s}$ of data, as the end of the time-series is expected to have the least noise due to terminal switching. The current measurement similarly used the average of the last $100 \mathrm{~s}$ of the $600 \mathrm{~s}$ of data. 
(See figure on next page.)

Fig. 13 Profiles of electrical potential in the circumferential direction $\theta$ at each $z$ from measurements using an electrode array. The coordinates $z$ and $\theta$ are defined in Fig. 12. a Profile at $z 1=16.7 \mathrm{~mm}, \mathbf{b}$ at $z 2=33.3 \mathrm{~mm}, \mathbf{c}$ at $z 3=50 \mathrm{~mm}, \mathbf{d}$ at $z 4=66.7 \mathrm{~mm}$, and $\mathbf{e}$ at $z 5=83.3 \mathrm{~mm}$. Left panels $(\mathbf{a} \mathbf{1}$ to $\mathbf{e}$ ) show the measured value with elapsed time $(60,100,200 \mathrm{~s}$, etc.) from the start of the measurement at each potential electrode. The symbols indicate the data acquisition time. The reference point for the measured potential distribution used for comparison with the numerical results is the midpoint between the current electrodes. Right panels show numerical results of forward modelling (a2 to $\mathbf{e} 2$ ). The orange and blue dots, respectively, indicate the experimental and numerical results. In experimental results, error bars are smaller than the symbols. Each measured value is the potential at each electrode averaged over the last $100 \mathrm{~s}$ of measurement. The numerical results were calculated by using the average of all $100 \mathrm{~s}$ current intensity data at the corresponding timing of potential observation. The measured values were normalised by the average current for comparison

Obtained potential distribution and modelling results Comparison of the measured potentials and the results of forward modelling with the optimum value of $\rho_{\text {sample }}$ is shown in Fig. 13a2-e2. All $z$ lines showed consistent measured and calculated potentials, indicating the validity of the measurement.

In addition, the resistivity obtained with the electrode array was consistent with the results of repeated measurements in six sequences when considering the effect of humidity. The resistivity determined with the electrode array was $6.7 \times 10^{5} \Omega \mathrm{m}$. The repeated measurements at relatively high humidity were performed at $20.3 \pm 0.5$ and $23.6 \pm 0.7 \mathrm{~g} / \mathrm{m}^{3}$ absolute humidity, whereas the array measurement was performed at $21.7 \mathrm{~g} / \mathrm{m}^{3}$ absolute humidity, which is between the two values of the repeated measurements. The corresponding resistivities determined in the repeated measurements were $(1.7 \pm 0.4) \times 10^{6}$ and $(1.4 \pm 1.0) \times 10^{5} \Omega \mathrm{m}$, respectively, and that determined by the array measurement fell between them, as expected given the humidity dependency of resistivity.

The array measurement will be applied to electrical tomography in combination with an inversion process. Electrical tomography has previously been considered possible only under restricted conditions such as high water-saturation (Stacey 2006). However, the present results for dry rock demonstrate that our procedure can facilitate tomographic measurements for a variety of targets under wider conditions than considered previously.

An interesting measurement target is one containing fractures. Compression tests of granite samples of the same size as used here have been widely performed, and to prepare samples with heterogeneous structures is not difficult. Comparison of electrical and CT measurement results may provide useful information about the electrical properties of heterogeneous structures. Previous studies have used CT imaging to investigate fracture distributions in granite samples (e.g., Kawakata et al. 1999).

\section{Conclusions}

We propose a reliable procedure for stable multi-point electrical measurements on a rock sample with high contact resistance. The method employs conductive epoxy adhesive electrodes to achieve secure attachment and high conduction on a dry rock surface. Stable current was injected into high-resistance samples using a constant direct current source with high internal resistance. Voltage was accurately measured in high-resistance samples via differential measurement with two high input resistance voltmeters. The problem of leakage current through the negative terminal of the voltmeter was solved by shorting it to the negative terminal of the current source. Contact resistance and potential fluctuation in the negative current electrode were eliminated by the differential measurement. Temperature and humidity in the laboratory were controlled using a humidifier, a dehumidifier, and a vinyl tent. Potential sources of signal noise from human activity were eliminated by using remote terminal switching and instrument operation.

We applied the new method to dry granite samples and evaluated its precision and stability under multiple absolute humidity conditions. At each humidity, the measurements were highly reproducible, thus indicating the stability of our new method. Nonetheless, atmospheric moisture did greatly influence the sample resistance and contact resistance, showing that humidity, alongside temperature, is an important environmental factor that must be controlled in the laboratory. Very high resistance exceeding $100 \mathrm{G} \Omega$ can be measured repeatedly by the new method even while using a small $100 \mathrm{~mm}^{2}$ electrode. We also applied the new method to multiple plastic samples of known resistivity to confirm the consistency of its resistivity results with bulk resistivity measurements.

We performed electrical measurements on a dry granite sample using many electrodes as the first step towards electrical tomography. The potential distribution calculated by forward modelling was consistent with the measured distribution, indicating the robustness of the measurement procedure and its potential capability for electrical tomography on high-resistance rock 

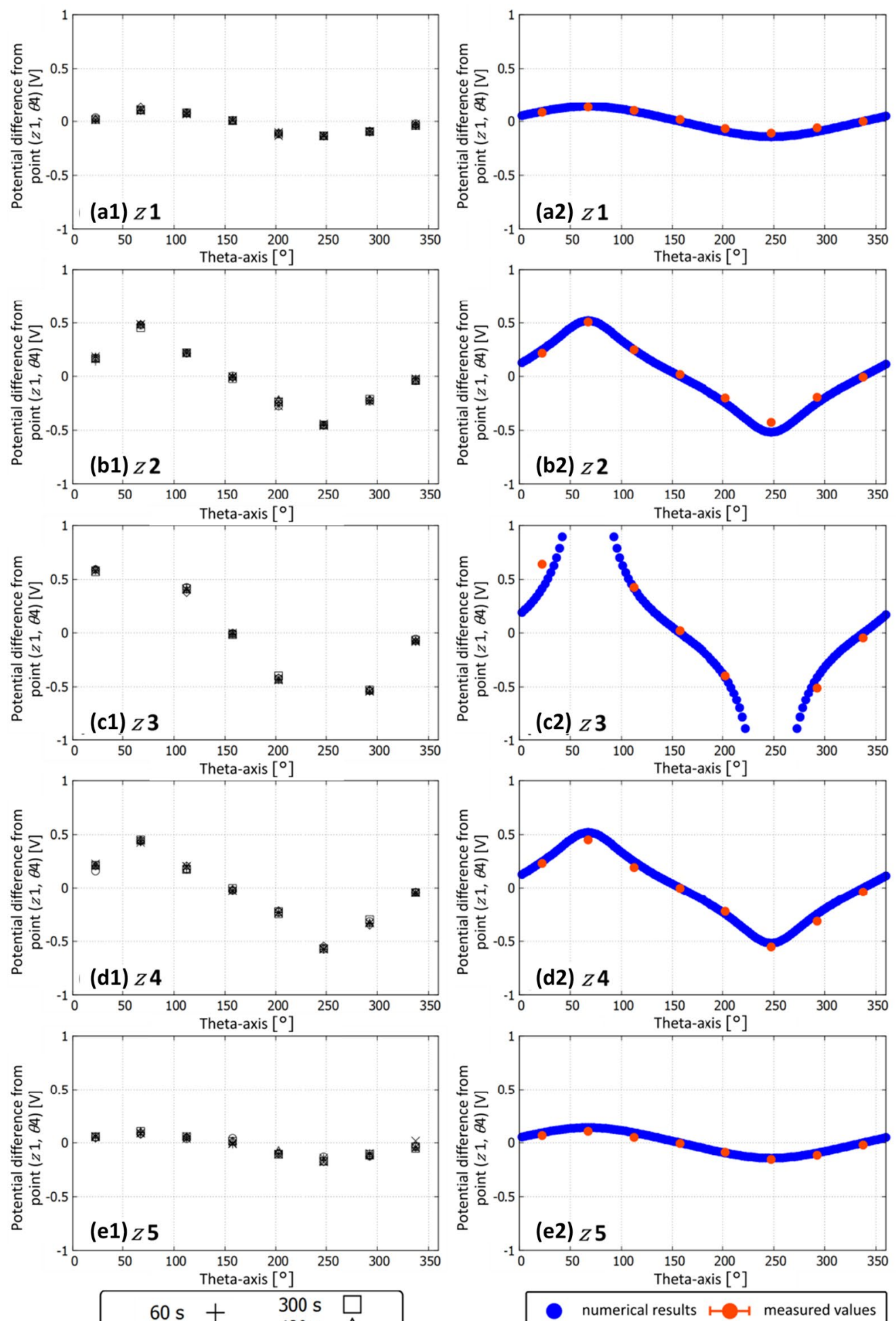

$$
\begin{aligned}
60 \mathrm{~s}+ & 300 \mathrm{~s} \\
100 \mathrm{~s} & \\
200 \mathrm{~s} & \triangle \\
500 \mathrm{~s} & \bigcirc \\
600 \mathrm{~s} & \diamond
\end{aligned}
$$


samples with high contact resistance (e.g., dry rocks). We also confirmed that the determined resistivity varied as expected with changing humidity.

\begin{abstract}
Abbreviations
$H_{\mathrm{A}}$ : Absolute humidity; $R_{\text {measured: }}$ Resistance measured between the current electrodes; $R_{\text {sample: }}$ Sample resistance between the current electrodes; $R_{\text {contact }}$ Contact resistance at the electrodes; $R_{\mathrm{IN}}$ : Input resistance; $R_{\mathrm{V}}$ : Insulation resistance between the negative terminal and chassis ground; $V_{\text {offet }}$ : Difference between the actual and calculated potentials at the reference point $(Z 1, \theta 4)$; $V_{P 1}-V_{P 2}$ : Potential difference between the potential electrodes; $V_{C 1}-V_{C 2}$ : Potential difference between the current electrodes; $V_{\text {uncorrected: }}$ Potential difference uncorrected for fluctuations in injection current intensity in array measurement; $V_{\text {corrected: }}$ Potential difference corrected for fluctuations in

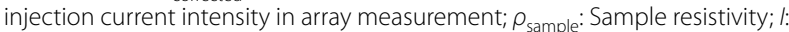
Injected current
\end{abstract}

\section{Acknowledgements}

We thank the National Research Institute for Earth Science and Disaster Resilience and the Research Institute for Sustainable Humanosphere, Kyoto University, for providing the measurement equipment used in this study. Futoshi Yamashita, Hironori Kawakata, and Yasuyuki Kano are thanked for their help at the early stage of this study. We also thank Takuto Minami, Ryousuke Umezawa and Shinichi Takakura for valuable comments that improved an earlier version of the manuscript. We are also grateful to anonymous reviewers and handling editors, Yasuo Ogawa and Kiyoshi Baba, for essential comments that improved our manuscript. Micro-focus X-ray CT measurements were performed under the cooperative research program (number 18B057) of the Center for Advanced Marine Core Research (CMCR), Kochi University. We thank Yuji Yamamoto, Masafumi Murayama, and Takuya Matsuzaki for technical support with the micro-focus $\mathrm{X}$-ray CT measurements.

\section{Authors' contributions}

TS developed the measurement method, applied the method to samples, interpreted the obtained results, led the discussion, and wrote the first draft of the manuscript. RY, KY, and NO contributed to analysis and interpretation of data, and assisted in the preparation of the manuscript. All authors revised and improved the manuscript. All authors read and approved the final manuscript.

\section{Funding}

This study was partially funded by the New Exploratory Research $(28 \mathrm{H}-02$, 29H-04) at the Disaster Prevention Research Institute, Kyoto University.

\section{Availability of data and materials}

The data that support the findings of this study are available upon request from the corresponding author.

\section{Declarations}

\section{Ethics approval and consent to participate}

Not applicable.

\section{Consent for publication}

Not applicable.

\section{Competing interests}

The authors declare that they have no competing interests.

\section{Author details}

${ }^{1}$ Graduate School of Science, Kyoto University, Gokasho, Uji, Kyoto 611-0011, Japan. ${ }^{2}$ Disaster Prevention Research Institute, Kyoto University, Gokasho, Uji, Kyoto 611-0011, Japan. ${ }^{3}$ Miyazaki Observatory, Research Center for Earthquake
Prediction, Disaster Prevention Research Institute, Kyoto University, 3884, Kaeda, Miyazaki 889-2161, Japan.

Received: 8 February 2021 Accepted: 24 May 2021

Published online: 07 June 2021

\section{References}

Alvarez R (1973) Effects of atmospheric moisture on rock resistivity. J Geophys Res 78(11):1769-1779

Borsic A, Comina C, Foti S, Lancellotta R, Musso G (2005) Imaging heterogeneities with electrical impedance tomography: laboratory results. Géotechnique 55(7):539-547

Brace WF, Orange AS, Madden TR (1965) The effect of pressure on the electrical resistivity of water-saturated crystalline rocks. J Geophys Res $70(22): 5669-5678$

Chiba A, Kumada M (1994) Resistivity measurement for granite and tuff samples-influence of pore fluid resistivity on rock resistivity. Butsuri-Tansa 47(4):161-172 (In Japanese with English abstract)

Collet LS (1959) Laboratory investigation of overvoltage. In: Wait JR (ed) Overvoltage research and geophysical applications. Pergamon Press, Oxford, pp 50-60

Colomer MT, Anderson MA (2001) High porosity silica xerogels prepared by a particulate sol-gel route: pore structure and proton conductivity. J NonCryst Solids 290(2-3):93-104

Coster HP (1948) The electrical conductivity of rocks at high temperatures. Geophys J Int 5:193-199

Dey A, Morrison HF (1979) Resistivity modeling for arbitrarily shaped threedimensional structures. Geophysics 44(4):753-780

Dickin F, Wang M (1996) Electrical resistance tomography for process applications. Meas Sci Technol 7(3):247-260

Fuji-ta K, Katsura T, Tainosho Y (2004) Electrical conductivity measurement of granulite under mid-to lower crustal pressure-temperature conditions. Geophys J Int 157(1):79-86

Fuji-ta K, Katsura T, Matsuzaki T, Ichiki M, Kobayashi T (2007) Electrical conductivity measurement of gneiss under mid-to-lower crustal P-T conditions. Tectonophys 434(1-4):93-101

Gee ML, Healy TW, White LR (1990) Hydrophobicity effects in the condensation of water films on quartz. J Colloid Interface Sci 140:450-546

Holder DS, Rao A, Hanquan Y (1996) Imaging of physiologically evoked responses by electrical impedance tomography with cortical electrodes in the anaesthetized rabbit. Physiol Meas 17(4A):A179

Karhunen K, Seppänen A, Lehikoinen A, Blunt J, Kaipio JP, Monteiro PJ (2010) Electrical resistance tomography for assessment of cracks in concrete. $\mathrm{ACl}$ Mater J 107(5):523-531

Kariya KA, Shankland TJ (1983) Electrical conductivity of dry lower crustal rocks. Geophys 48(1):52-61

Kawakata H, Cho A, Kiyama T, Yanagidani T, Kusunose K, Shimada M (1999) Three-dimensional observations of faulting process in Westerly granite under uniaxial and triaxial conditions by X-ray CT scan. Tectonophysics 313(3):293-305

Mazzoco RR, Wayner PC Jr (1999) Aqueous wetting films on fused quartz. J Colloid Interface Sci 214:156-169

Meier T, Luepschen H, Karsten J, Leibecke T, Großherr M, Gehring H, Leonhardt $S$ (2008) Assessment of regional lung recruitment and derecruitment during a PEEP trial based on electrical impedance tomography. Intensive Care Med 34(3):543-550

Mitsubishi Chemical Advanced Materials (2020a) MC Nylon MC501CD R2 (electro conductive grade). https://www.mcam.com/jp-en/products/ engineering-plastics/engineering-80-160/extruded-cast-nylons/mc501 cd-r2/. Accessed 31 Dec 2020

Mitsubishi Chemical Advanced Materials (2020b) MC Nylon MC500AS R11 (noncarbon antistatic grade). https://www.mcam.com/jp-en/products/ 
engineering-plastics/engineering-80-160/extruded-cast-nylons/mc500 as-r11/. Accessed 31 Dec 2020

Okuyama Y (1973) The effects of water content on the electrical resistivity of rocks. Bull Akita Natl Coll Technol 8:110-114 (In Japanese)

Pashley RM, Kitchener JA (1979) Surface forces in adsorbed multilayers of water on quartz. J Colloid Interface Sci 71:491-500

Soffer A, Folman M (1966) Surface conductivity and conduction mechanisms on adsorption of vapours on silica. Trans Faraday Soc 62:3559-3569

Stacey R (2006) Electrical impedance tomography. Geothermal Program Interdisciplinary Research in Engineering and Earth Sciences. In: Tech Rep SGP-TR-182. Stanford University.

Suzuki T, Yoshimura R, Yamazaki K (2017) Oshiman N (2017) Potential modeling for cylindrical shaped structures. Disaster Prevent Res Inst Annu B 60(b):373-381 (In Japanese with English abstract)
Tektronix (2016) Low level measurements handbook, 7th edn. Tektronix Beaverton

Umezawa R, Katsura M, Nakashima S (2018) Electrical conductivity at surfaces of silica nanoparticles with adsorbed water at various relative humidities. e-J Surf Sci Nanotechnol 16:376-381

Yamashita F, Fukuyama E, Mizoguchi K (2014) Probing the slip-weakening mechanism of earthquakes with electrical conductivity: rapid transition from asperity contact to gouge comminution. Geophys Res Lett $41(2): 341-347$

\section{Publisher's Note}

Springer Nature remains neutral with regard to jurisdictional claims in published maps and institutional affiliations.

\section{Submit your manuscript to a SpringerOpen ${ }^{\circ}$ journal and benefit from:}

- Convenient online submission

- Rigorous peer review

- Open access: articles freely available online

- High visibility within the field

- Retaining the copyright to your article

Submit your next manuscript at $\boldsymbol{\nabla}$ springeropen.com 